\title{
Effects of high surface energy on lithium-ion intercalation properties of $\mathrm{Ni}$-doped $\mathrm{Li}_{3} \mathrm{VO}_{4}$
}

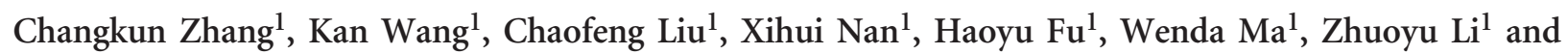 \\ Guozhong Cao ${ }^{1,2}$
}

Nickel was doped into $\mathrm{Li}_{3} \mathrm{VO}_{4}$ (Ni-LVO) successfully via a facile room temperature reaction, and the resulting Ni-LVO nanocrystallites showed excellent lithium-ion storage properties with a capacity of $650 \mathrm{mAh} \mathrm{g}^{-1}$ at $50 \mathrm{mAh} \mathrm{g}^{-1}$ and excellent capacity stability as an anode in lithium-ion batteries, maintaining nearly $100 \%$ of the initial reversible capacity after 800 cycles at $1 \mathrm{Ag}^{-1}$. The superior electrochemical properties arose largely from the nickel doping in the Ni-LVO. The surface energy of the electrode material was analyzed by an inverse gas chromatography method, and the Ni-LVO surface energy, $43.91 \mathrm{~mJ} \mathrm{~m}^{-2}$, was much higher than the $30.74 \mathrm{~mJ} \mathrm{~m}^{-2}$ of $\mathrm{Li}_{3} \mathrm{VO}_{4}$. X-ray photoelectron spectra results demonstrated that nickel doping promoted the formation of tetravalent vanadium ions, $\mathrm{V}^{4+}$, as well as a more amorphous surface of $\mathrm{Li}_{3} \mathrm{VO}_{4}$, thus probably resulting in more nucleation sites for the phase transformation and reduced activation energy of the redox reactions and phase transition during the lithium-ion intercalation/extraction processes.

NPG Asia Materials (2016) 8, e287; doi:10.1038/am.2016.95; published online 22 July 2016

\section{INTRODUCTION}

$\mathrm{Li}_{3} \mathrm{VO}_{4}$ (LVO), whose structure consists of corner-sharing $\mathrm{VO}_{4}$ and $\mathrm{LiO}_{4}$ tetrahedra, has been studied as a promising anode material for lithium-ion batteries. ${ }^{1,2}$ It possesses several advantages over other anode materials. First, LVO has a small structural and volume change during lithiation/delithiation processes, thus resulting in good cyclic durability. ${ }^{3}$ Second, it has high ionic conductivity $\left(\sim 10^{-4} \mathrm{~S} \mathrm{~cm}^{-1}\right)$, which facilitates the effective diffusion of lithium ions in bulk. ${ }^{4}$ Third, compared with $\mathrm{Li}_{4} \mathrm{Ti}_{5} \mathrm{O}_{12}$, LVO can intercalate lithium ions in a low-voltage region (between 0.5 and $1.0 \mathrm{~V}$ vs $\mathrm{Li} / \mathrm{Li}^{+}$), thus eventually offering a high full cell energy density and maintaining good safety. ${ }^{3,5}$ Finally, the hollow, lantern-like, three-dimensional structure of LVO crystal provides many empty sites to accommodate lithium ions and serves as lithium ion insertion channels. Theoretical calculations indicate that the inserted lithium ions have two different Wyckoff sites, which are stably occupied by three external lithium ions corresponding to a theoretical capacity of $591 \mathrm{mAh} \mathrm{g}^{-1}$ when discharged to $0.01 \mathrm{~V}$ vs $\mathrm{Li} / \mathrm{Li}^{+}$.

Despite these advantages, LVO suffers from low electrical conductivity, which may cause large polarization and poor rate capability. Hybridization with carbon materials such as graphite, ${ }^{7,8}$ carbon nanotubes ${ }^{9}$ and graphene $e^{10,11}$ and reduction of the LVO particle size have been proven to be effective ways to enhance electrical conductivity and abate polarization. For example, carbon-encapsulated LVO nanoparticles synthesized by a simple solid-state method exhibit excellent rate capability and long cycling performance. ${ }^{1}$ In addition, defects introduced by doping, thermal treatment at an inert or reducing atmosphere, and control of synthesis methods may also affect the chemical composition, lattice distortion and the crystal field, thus eventually improving the electrochemical performance of the materials. ${ }^{12}$ Yang and co-workers group have found that the amorphous and oxygen-deficient surface of LVO enhances chargetransfer kinetics, thus resulting in great improvements in reversible capacity. ${ }^{13}$ Nickel doping into metal oxides is one effective strategy for improving the electrochemical insertion process, offering electric stability and mitigating Jahn-Teller distortion. ${ }^{14}$

In this paper, nickel was introduced into LVO to investigate its effects on the structure and electrochemical performance of LVO. An inverse gas chromatography method ${ }^{15,16}$ was first used to identify the effects of nickel doping on the surface energy, and it was found that the resultant nickel-doped LVO (Ni-LVO) exhibited high surface energy and capability of $650 \mathrm{~mA} \mathrm{~g}^{-1}$ at $50 \mathrm{~mA} \mathrm{~g}^{-1}$. At 2 and $4 \mathrm{Ag}^{-1}$, it maintained a reversible capability of 267 and $191 \mathrm{mAh} \mathrm{g}^{-1}$, respectively. After 800 cycles at $1 \mathrm{Ag}^{-1}$, the nickel-doped LVO material was able to deliver nearly $100 \%$ capacity retention.

\section{EXPERIMENTAL PROCEDURES}

\section{Material synthesis and characterization}

A total of $10 \mathrm{mmol} \mathrm{LiOH} \cdot \mathrm{H}_{2} \mathrm{O}$ was dissolved in water by stirring and denoted solution A. A total of $1.67 \mathrm{mmol} \mathrm{V}_{2} \mathrm{O}_{5}$ and $2.5 \mathrm{mmol} \mathrm{Ni}\left(\mathrm{NO}_{3}\right)_{2} \cdot 6 \mathrm{H}_{2} \mathrm{O}$ were dispersed in ethanol by sonication for $20 \mathrm{~min}$ and denoted solution $\mathrm{B}$. The volume ratio of solution B to solution A was 3:1. Solution A was then slowly added into solution $\mathrm{B}$. The mixture was stirred for $5 \mathrm{~h}$ at room temperature $\left(\sim 20^{\circ} \mathrm{C}\right)$. The Ni-LVO sample was synthesized after being dried at $60^{\circ} \mathrm{C}$ for

\footnotetext{
${ }^{1}$ Beijing Institute of Nanoenergy and Nanosystems, Chinese Academy of Sciences, National Center for Nanoscience and Technology (NCNST), Beijing, China and ${ }^{2}$ Department of Materials Science and Engineering, University of Washington, Seattle, WA, USA

Correspondence: Professor G Cao, Department of Materials Science and Engineering, University of Washington, 302M Roberts Hall, Seattle, WA 98195-2120, USA. E-mail: gzcao@u.washington.edu

Received 11 March 2016; revised 13 May 2016; accepted 19 May 2016
} 

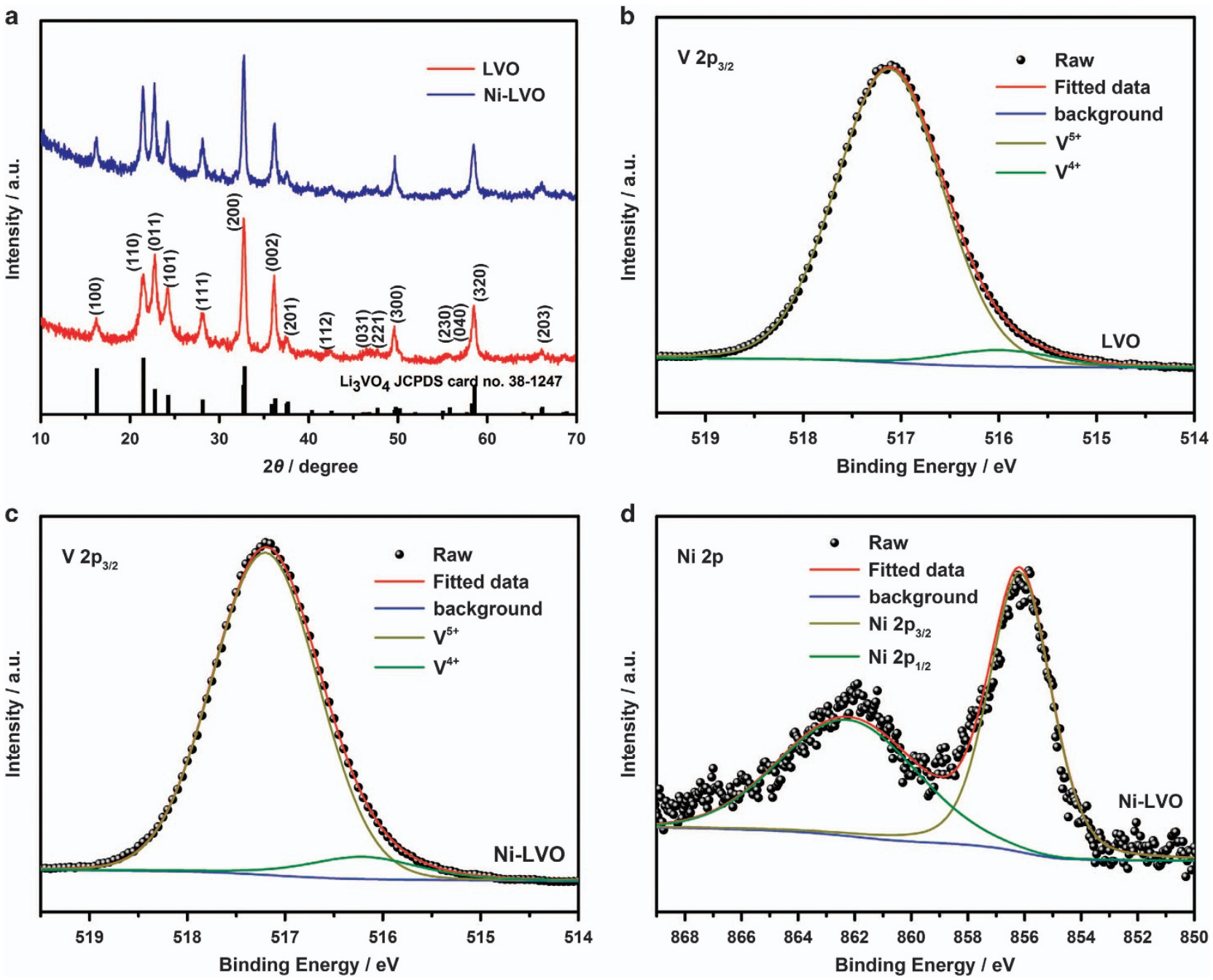

Figure 1 (a) XRD patterns of the LVO and Ni-LVO samples. (b, c) V 2p XPS spectra of the LVO and Ni-LVO. (d) Ni 2p XPS of the Ni-LVO. XPS, X-ray photoelectron spectra; XRD, X-ray diffraction.

$12 \mathrm{~h}$. The white LVO without nickel doping was also prepared under the same conditions.

The phases of the samples were tested by X-ray diffraction (MXP21 VAHF) using the $\mathrm{Cu} \mathrm{K}_{\alpha}$ radiation $(\lambda=1.5418 \AA)$. The morphologies of the samples were characterized by field-emission scanning electron microscopy (SU8020) and transmission electron microscopy (JEOL JEM-2010). The surface area was measured by $\mathrm{N}_{2}$ adsorption-desorption analyses (ASAP 2020 HD88). X-ray photoelectron spectra were collected on an X-ray photoelectron spectrometer (ESCALAB 250Xi) using the C $1 \mathrm{~s}$ photoelectron peak at $284.6 \mathrm{eV}$ as the reference.

The surface energy of the samples was measured with an inverse gas chromatography Surface Energy Analyser (SEA, Surface Measurement Systems Ltd., London, UK). The columns were pretreated at $120^{\circ} \mathrm{C}$ for $3 \mathrm{~h}$ under a helium flow before any measurements were taken. Experiments were carried out at a column temperature of $25{ }^{\circ} \mathrm{C}$. Helium was used as carrier gas with a flow rate of $25 \mathrm{ml} \mathrm{min}^{-1}$. For the dispersive surface energy, the probes were $n$-hexane, $n$-heptane, $n$-octane and $n$-nonane. Methane was used as a dead time probe. The retention times $(\tau)$ were the averages of two injections and were determined by the Conder and Young method. The fractional surface coverage was 0.05 for both LVO and Ni-LVO samples. The dispersive surface energy was calculated using the Schultz method. For acid-base surface energy determination, mono-polar probes, dichloromethane and ethylacetate were also injected; however, no elution was detected, owing to strong interaction of these probes with the analyzed materials.

\section{Electrochemical characterization}

Electrochemical performance was evaluated with standard CR2032 coin cells. The working electrode was bladed on $\mathrm{Cu}$ foil with $75 \mathrm{wt} \%$ of active material, $20 \mathrm{wt} \%$ of acetylene black and $5 \mathrm{wt} \%$ of sodium carboxymethyl cellulose as a binder. The active material loading was $\sim 1 \mathrm{mg} \mathrm{cm}^{-2}$. The electrode was then dried at $120^{\circ} \mathrm{C}$ for $12 \mathrm{~h}$. The separator was NKK TF4840, and the electrolyte was $1 \mathrm{M} \mathrm{LiPF}_{6}$ solution in ethylene carbonate (EC)/dimethyl carbonate (DMC) ( $\mathrm{EC} / \mathrm{DMC}=1: 1$ in volume). Li metal was used as the counter and reference electrode. All cells were assembled in a glove box filled with water and oxygen $<0.1$ p.p.m. The galvanostatic discharging/charging curves were evaluated with a LAND (Wuhan, China) automatic battery tester. Electrochemical impedance spectroscopy and cyclic voltammetry were measured with a Solartron Instrument. The frequency of the electrochemical impedance spectroscopy measurement ranged from $100 \mathrm{kHz}$ to $0.1 \mathrm{~Hz}$.

\section{RESULTS AND DISCUSSION}

$\mathrm{Ni}-\mathrm{LVO}$ was synthesized in a mixture of water and ethanol through the room-temperature method. During the synthesis, the yellow solution quickly changed to white. The pale yellow Ni-LVO sample was collected after being dried at $60^{\circ} \mathrm{C}$ for $12 \mathrm{~h}$. The white LVO without nickel doping was also prepared under the same conditions. In this method, ethanol has an important role in the resulting LVO phase; without ethanol, only a homogeneous yellow solution was 

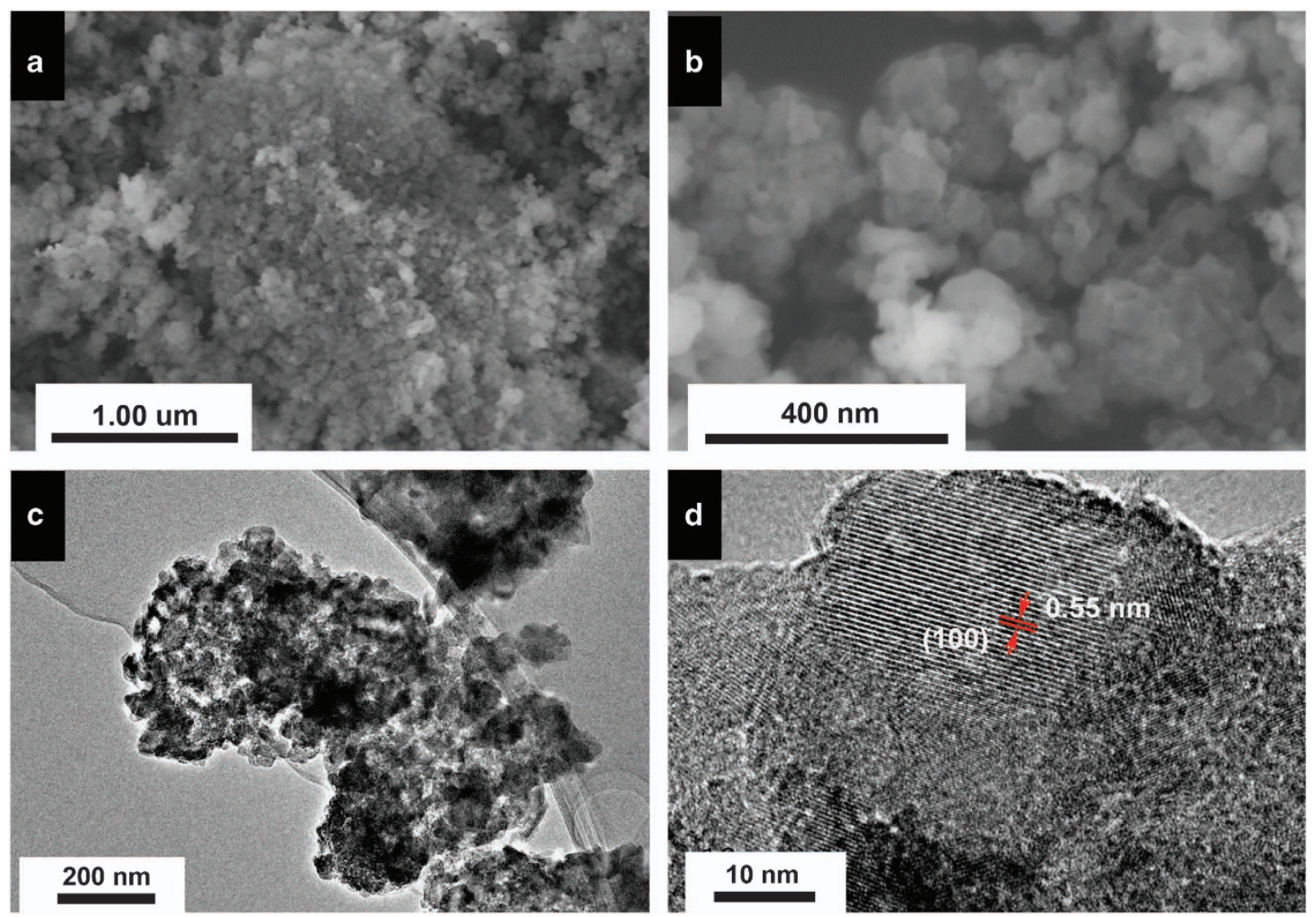

Figure 2 (a, b) SEM images of the LVO and Ni-LVO samples; (c, d) TEM images of the Ni-LVO sample. SEM, scanning electron microscopy; TEM, transmission electron microscopy.

generated. Figure 1a shows the X-ray diffraction patterns of the samples. Both samples exhibited crystals in the pure LVO orthorhombic phase (JCPDS No. 38-1247) with comparable crystallinity and without any detectable secondary or parasitic phase. LVO was obtained at room temperature without the use of organic ligands or surfactants. Nickel doping did not introduce any impurities into the Ni-LVO sample. Energy dispersive X-ray spectroscopy confirmed that the nickel was homogeneously distributed throughout the entire LVO crystals, thus suggesting that nickel was incorporated into the LVO crystal lattice (Supplementary Figure S1). The elemental mapping images in Supplementary Figure S1 display the existence and distribution of $\mathrm{V}, \mathrm{O}$ and $\mathrm{Ni}$ elements, indicating that nickel was distributed uniformly in the Ni-LVO sample. The Ni/V molar ratio was $8.4 \%$, which was similar to the value $(8.9 \%)$ provided by $\mathrm{X}$-ray photoelectron spectra. The higher $\mathrm{Ni} / \mathrm{V}$ ratio compared with that of the raw material $(7.5 \%)$ showed that more doped nickel was distributed on the outer layer of Ni-LVO. The grain sizes were 24.5 and $21.8 \mathrm{~nm}$ for the $\mathrm{LVO}$ and Ni-LVO samples, respectively, as calculated using the Debye-Scherrer equation based on the X-ray diffraction (111) patterns shown in Figure 1a. The crystallinity was $52.2 \%$ and $43.8 \%$ for LVO and Ni-LVO samples, respectively, suggesting that the presence of nickel not only promoted the initial nucleation but also retarded subsequent crystal growth. Low crystallization has been shown to accelerate the lithium ion interaction in the bulk. ${ }^{17,18}$ The lattice constants calculated from the X-ray diffraction results were $a=5.454, b=6.322$ and $c=4.954 \AA$ for pristine LVO and $a=5.543, b=6.323$ and $c=4.965 \AA$ for Ni-LVO. The change in lattice constants could be derived from the larger radius of $\mathrm{Ni}^{2+}$ $(0.69 \AA)$ than $\mathrm{V}^{5+}(0.54 \AA)$, thus suggesting the incorporation of nickel into the LVO crystal structure.
The surface composition and the valence states of the elements were characterized by X-ray photoelectron spectra. Figures $1 \mathrm{~b}, \mathrm{c}$ show the $\mathrm{V} 2 \mathrm{p}_{3 / 2}$ and Ni 2p X-ray photoelectron spectra spectra of LVO and $\mathrm{Ni}-\mathrm{LVO}$ samples. The peaks at 517.2 and $516.1 \mathrm{eV}$ were ascribed to $\mathrm{V}$ in the pentavalent state $\left(\mathrm{V}^{5+}\right)$ and tetravalent state $\left(\mathrm{V}^{4+}\right)$, respectively. From the relative areas of the $\mathrm{V}^{5+}$ and $\mathrm{V}^{4+}$ contributions, the molar ratio of $\mathrm{V}^{4} / \mathrm{V}^{5+}$ was estimated to be $8.4 \%$ for the Ni-LVO, which is 1.5 times that $(5.6 \%)$ of LVO. Therefore, nickel doping promoted the formation of low-valence-state vanadium in the Ni-LVO sample. When one pentavalent vanadium ion was substituted with a divalent nickel ion in Ni-LVO, one-and-half oxygen vacancies formed to attain electroneutrality. Oxygen vacancies arising from the need to maintain electroneutrality when $\mathrm{V}^{5+}$ reduces to $\mathrm{V}^{4+}$ might serve as nucleation centers for phase transformation during lithium ion intercalation/ deintercalation processes, as has been confirmed in other nickel-doped materials. ${ }^{14,19}$ For the Ni-LVO sample in Figure 1d, the two peaks at $856.1 \mathrm{eV}\left(\mathrm{Ni} 2 \mathrm{p}_{1 / 2}\right)$ and $862.2 \mathrm{eV}\left(\mathrm{Ni} 2 \mathrm{p}_{3 / 2}\right)$ are associated with the divalent nickel ions in $\mathrm{Ni}(\mathrm{II})$ oxide. ${ }^{20}$ Oxygen vacancies must compensate for the low-valent state of divalent nickel ions taking place at the substitutional sites in the LVO lattice.

The scanning electron microscopy and transmission electron microscopy images in Figure 2 present the morphologies of the LVO and Ni-LVO samples. The transmission electron microscopy image in Figure $2 \mathrm{c}$ shows that the Ni-LVO had many small nanocrystallites in the range of 25-60 $\mathrm{nm}$, and many nanocrystallites aggregated into large particles. From the scanning electron microscopy images (Figures 2a,b), both the synthesized LVO and Ni-LVO showed large particle sizes $(\sim 50-180 \mathrm{~nm})$, corresponding to the nitrogen adsorption/desorption results, and the Ni-LVO had slightly smaller particle sizes than the LVO. The transmission electron microscopy image of Ni-LVO in Figure 2d shows a lattice space of $0.55 \mathrm{~nm}$, which 


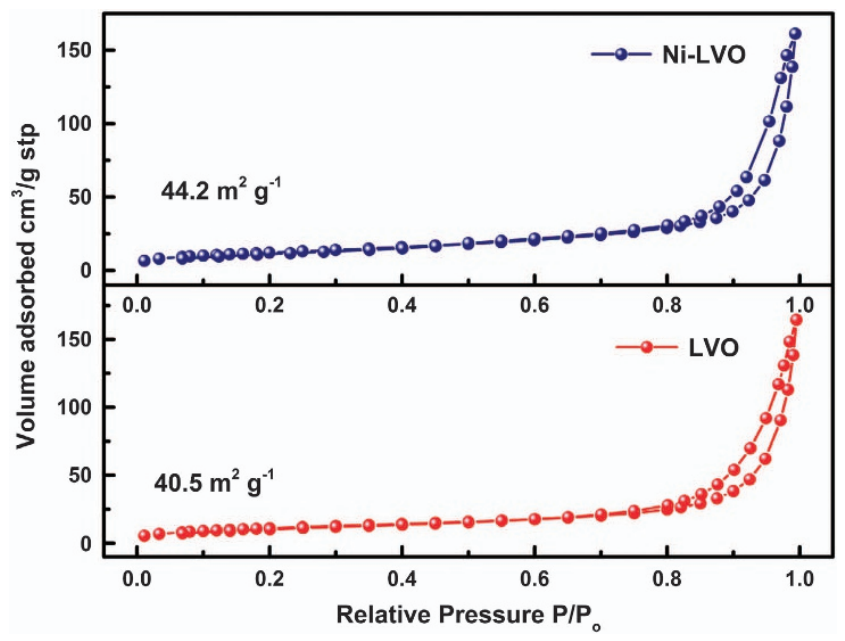

Figure 3 The $\mathrm{N}_{2}$ adsorption/desorption isotherm of the LVO and Ni-LVO samples.

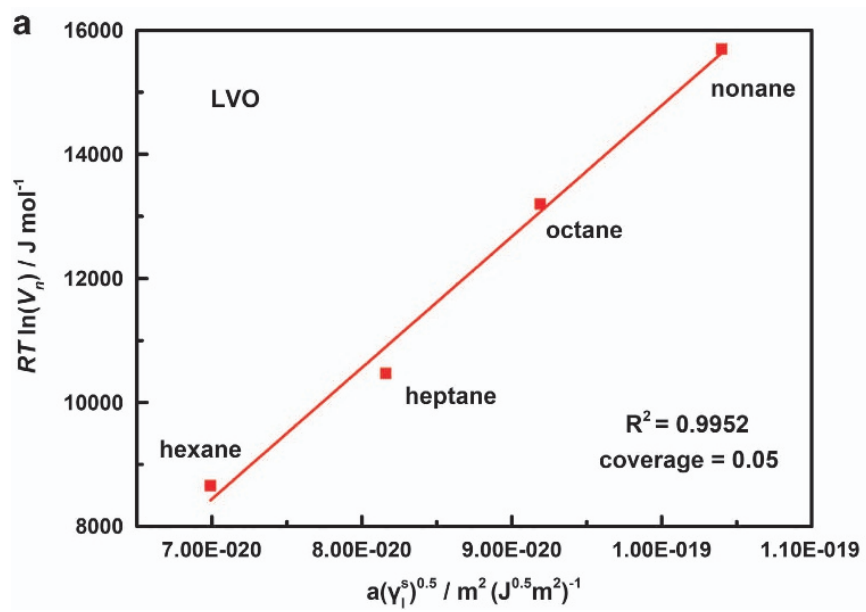

Figure $4(\mathbf{a}, \mathbf{b})$ Plots of $R \operatorname{Tn}\left(V_{n}\right)$ vs a $\left(\gamma_{j}^{d}\right)^{0.5}$ for the LVO and Ni-LVO materials.

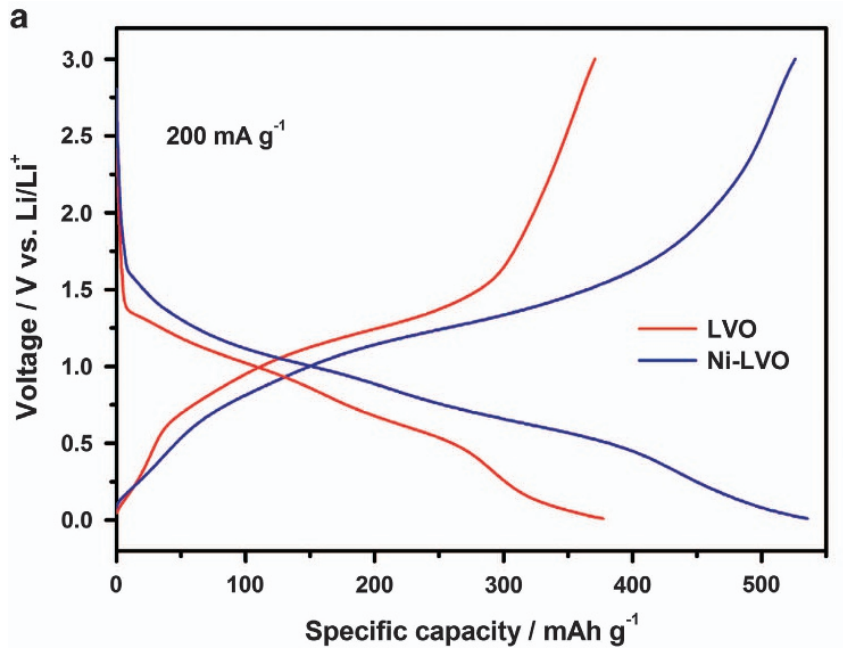

was identified as the (100) face. Figure 3 shows the curves of the nitrogen adsorption/desorption isotherm of the LVO and Ni-LVO samples. They all exhibited the typical III isotherm with a distinct hysteresis loop. The specific surface areas were calculated to be 40.5 and $44.2 \mathrm{~m}^{2} \mathrm{~g}^{-1}$ for the LVO and Ni-LVO samples, respectively. Nitrogen adsorption/desorption analyses revealed that the average particle sizes of LVO and Ni-LVO samples were 148.1 and $135.8 \mathrm{~nm}$, respectively, corresponding to the scanning electron microscopy image results, which were much larger than the grain sizes, thus suggesting that both the LVO and Ni-LVO nanocrystals synthesized at low temperatures formed large aggregates. The smaller particle size and larger surface area of $\mathrm{Ni}$-LVO might increase the interface of the material and electrolyte and facilitate lithium ion transport.

The surface energies of the samples was measured with an inverse gas chromatography method. $n$-Hexane, $n$-heptane, $n$-octane and $n$-nonane were used as probes to measure the dispersive surface energy. The dispersive surface energy was calculated using the Schultz method. ${ }^{16,21-23}$ Briefly, the retention of a gas probe molecule is quantified by the net retention volume, $V_{\mathrm{n}}$, defined as the amount of

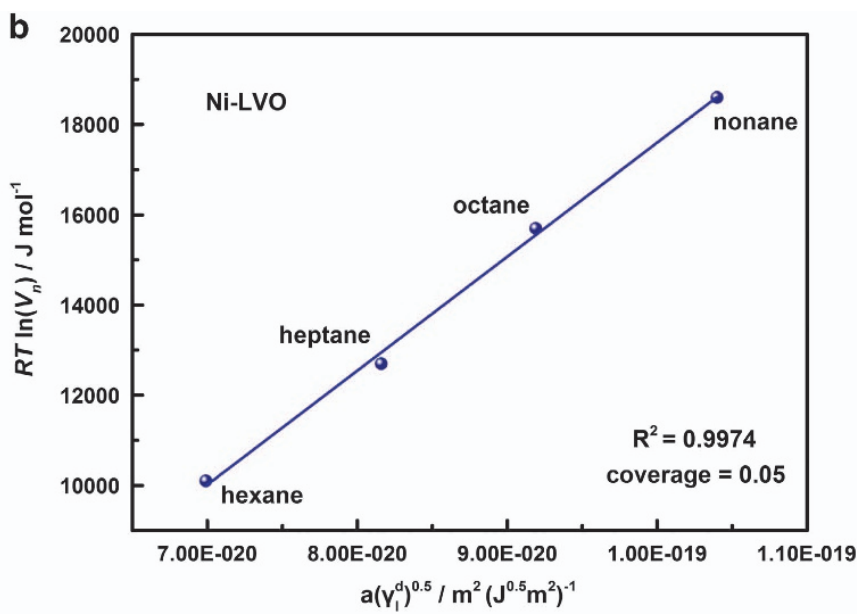

Figure 5 (a) Discharge and charge curves of LVO and Ni-LVO electrodes after 10 cycles at $200 \mathrm{~mA} \mathrm{~g}^{-1}$. (b) CV curves of the LVO and Ni-LVO electrodes for the second cycles with a scan rate of $0.2 \mathrm{mV} \mathrm{s}^{-1}$. CV, cyclic voltammetry.

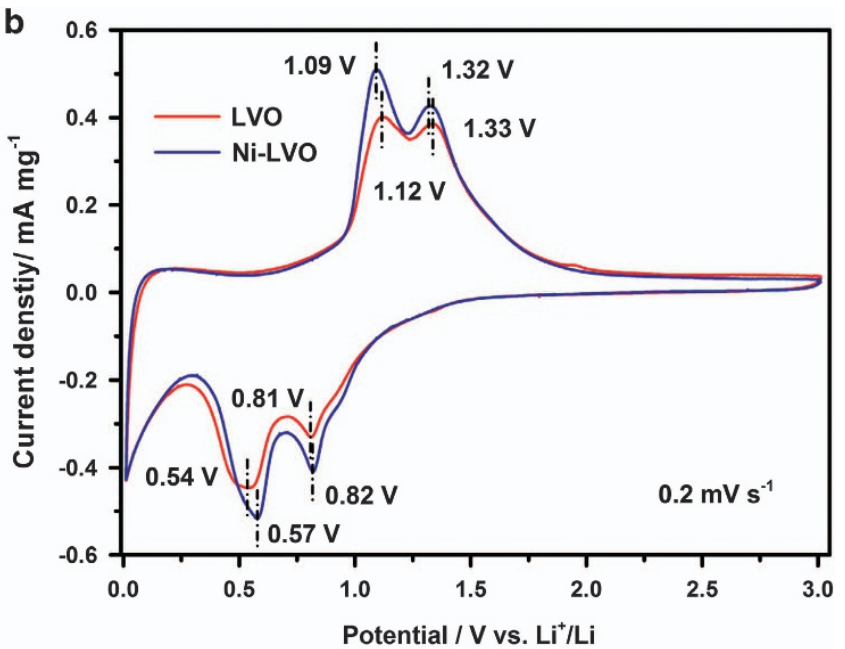


carrier gas required to elute the injected volume of probe molecules from the column. At infinite dilution, in which probe-probe interactions are negligible and $V_{\mathrm{n}}$ depends only on the sample-probe interactions, the free energy of adsorption of the probe on the stationary phase surface per mole, $\Delta G_{\mathrm{a}}$, can be determined from $V_{\mathrm{n}}$, according to equation (1): ${ }^{15,16}$

$$
\Delta G_{\mathrm{a}}=-R T \ln \left(V_{\mathrm{n}}\right)+K
$$

where $R$ is the gas constant, $T$ is the absolute column temperature and $K$ is a constant dependent on the chosen reference state. $\Delta G_{\mathrm{a}}$ can also

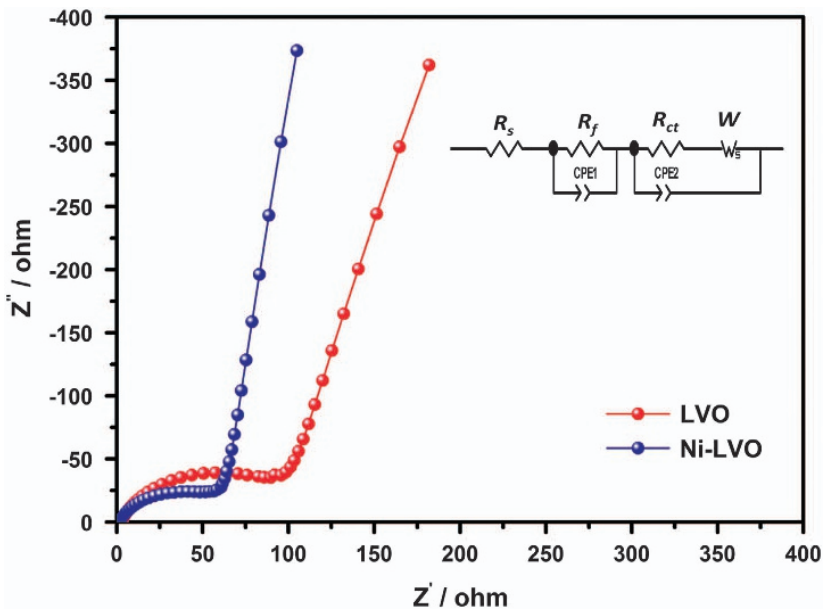

Figure 6 Nyquist plots for the LVO and Ni-LVO electrodes (the AC amplitude was $5 \mathrm{mV}$ and at $2.68 \mathrm{~V}$ vs $\mathrm{Li} / \mathrm{Li}^{+}$) CV curves of the LVO and $\mathrm{Ni}-\mathrm{LVO}$ electrodes for the second cycles with a scan rate of $0.2 \mathrm{mV} \mathrm{s}^{-1}$. $\mathrm{CV}$, cyclic voltammetry. be determined by the work of adhesion $\left(W_{\mathrm{A}}\right)$ between the vapor probe and the solid stationary phase per unit surface area: ${ }^{24}$

$$
-\Delta G_{\mathrm{a}}=N a W_{\mathrm{A}}
$$

where $N$ is Avogadro's number and $a$ is the surface area of an adsorbed probe molecule. When only dispersive interaction occurs between the sample and probe, earlier studies have found that $W_{\mathrm{A}}$ is equal to twice the geometric mean of the dispersive components of the surface energy of the liquid $\left(\gamma_{l}^{d}\right)$ and the stationary phase $\left(\gamma_{\mathrm{s}}^{d}\right):{ }^{25}$

$$
W_{\mathrm{A}}=2\left(\gamma_{\mathrm{s}}^{d} \gamma_{1}^{d}\right)^{0.5}
$$

A combination of equations (1-3) leads to the statement

$$
R T \ln \left(V_{\mathrm{n}}\right)=\sqrt{\gamma_{\mathrm{s}}^{d}} 2 N a \sqrt{\gamma_{1}^{d}}+K
$$

Thus, the dispersive surface energy may be estimated from the slope of the linear fit of $R T \ln \left(V_{\mathrm{n}}\right)$ as a function of a $\left(\gamma_{1}^{d}\right)^{0.5}$.

As shown in Figure 4, the plots of $R T \ln \left(V_{\mathrm{n}}\right)$ against a $\left(\gamma_{1}^{d}\right)^{0.5}$ of LVO and Ni-LVO samples were linear. According to the linear fit, the dispersive surface energy was calculated to be 30.7 and $43.9 \mathrm{~mJ} \mathrm{~m}^{-2}$ for LVO and Ni-LVO samples, respectively. The enhanced surface energy of Ni-LVO may have occurred because nickel doping induced more amorphousness and defects at the surface. The surface energy of LVO materials in our work was lower than that of other metal oxides, such as $\mathrm{CaO}\left(79.0 \mathrm{~mJ} \mathrm{~m}^{-2}\right),{ }^{26} \mathrm{MgO}\left(74.2 \mathrm{~mJ} \mathrm{~m}^{-2}\right)^{26}$ and $\mathrm{ZnO}$ $\left(85.1 \mathrm{~mJ} \mathrm{~m}^{-2}\right)^{27}$ because of different test temperatures.

Figure $5 \mathrm{a}$ shows the galvanostatic discharge and charge curves of the LVO and Ni-LVO electrodes at the current density of $200 \mathrm{~mA} \mathrm{~g}^{-1}$; the discharge capacity of the $\mathrm{Ni}-\mathrm{LVO}$ was $535 \mathrm{mAh} \mathrm{g}^{-1}$, which was much higher than that of $\operatorname{LVO}\left(377 \mathrm{mAh} \mathrm{g}^{-1}\right)$. From the flat charge/ discharge difference of the electrodes, the Ni-LVO had lower

\begin{tabular}{|c|c|c|c|c|c|}
\hline Samples & Discharge capacity at $50 \mathrm{~mA} \mathrm{~g}^{-1} / \mathrm{mAh} \mathrm{g}^{-1}$ & Dispersive surface energy $/ \mathrm{mJ} \mathrm{m}^{-2}$ & Offsets of redox peaks & $R_{\mathrm{ct}} / \Omega$ & $D / \mathrm{cm}^{2} \mathrm{~s}^{-1}$ \\
\hline $\mathrm{Ni}-\mathrm{LVO}$ & 650 & 43.91 & $0.52 / 0.5 \mathrm{~V}$ & 62 & $2.02 \times 10^{-15}$ \\
\hline
\end{tabular}
polarization than the LVO. The lower polarization may have resulted from the nickel doping onto the LVO in the Ni-LVO sample.

Table 1 The discharge capacity, $\gamma_{\mathrm{s}}^{\mathrm{d}}, R_{\mathrm{ct}}$ and $D$ of the LVO and LVO/C-600 samples

Abbreviations: $\mathrm{LVO}, \mathrm{Li}_{3} \mathrm{VO}_{4} ; \mathrm{Ni}-\mathrm{LVO}$, nickel doped into LVO.
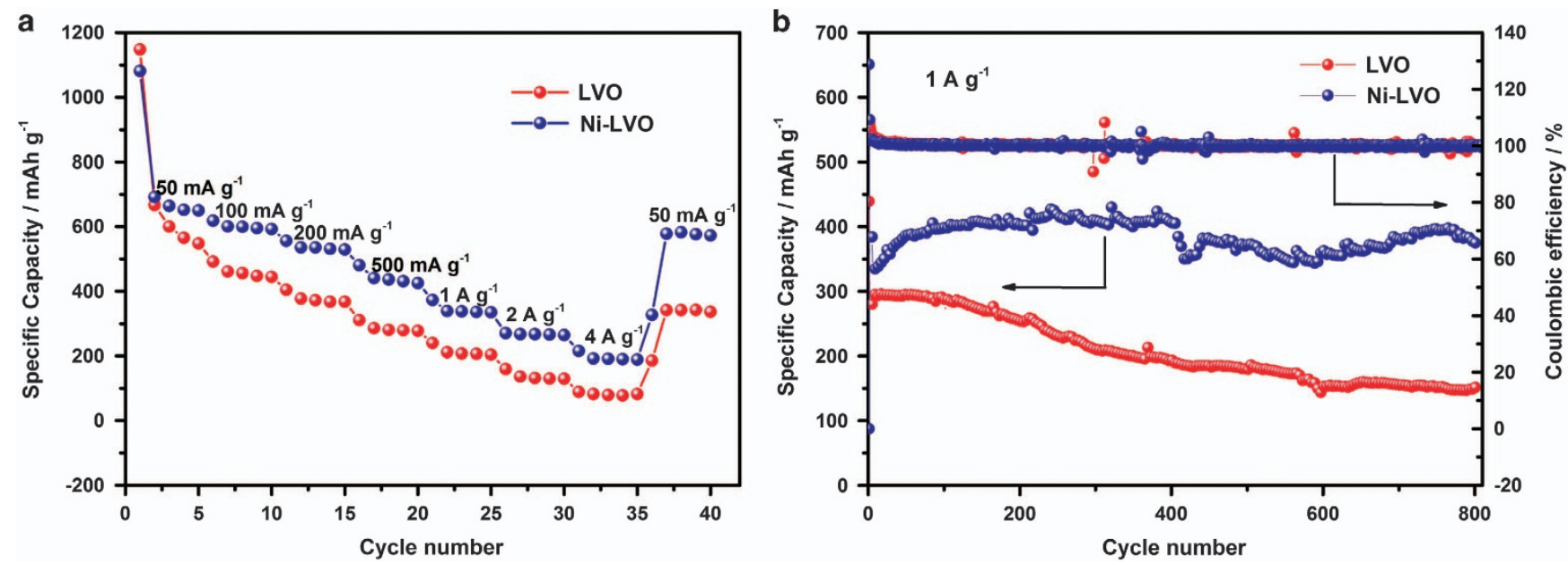

Figure 7 (a) Discharge capacities of the electrodes at various rates; (b) capacity retention and coulombic efficiency of LVO and Ni-LVO at 1 A g ${ }^{-1}$. 
Figure $5 \mathrm{~b}$ shows the cyclic voltammetry curves of the electrodes for the second cycles at $0.2 \mathrm{mV} \mathrm{s}^{-1}$. For the LVO electrode, two reduction peaks were found at 0.54 and $0.81 \mathrm{~V}$, which were attributed to the insertion of $\mathrm{Li}^{+}$into $\mathrm{LVO}$, and two oxidation peaks at 1.12 and $1.33 \mathrm{~V}$ correspond to the oxidation of LVO. For the Ni-LVO electrode, two pairs of redox peaks appeared at $0.57 / 1.09 \mathrm{~V}$ and $0.82 / 1.32 \mathrm{~V}$. The polarization of the cathode in the charge/discharge process could be restrained effectively, as confirmed in Figure 5a; the potential offsets between the oxidative peak and reductive peak of nickel-doped LVO material were only 0.52 and $0.5 \mathrm{~V}$, markedly lower than the offset for pure LVO $(0.58$ and $0.52 \mathrm{~V})$.

Electrochemical impedance spectroscopy measurement was carried out between $100 \mathrm{kHz}$ and $0.1 \mathrm{~Hz}$ at $2.68 \mathrm{~V}$ vs $\mathrm{Li} / \mathrm{Li}^{+}$. The Nyquist plots (Figure 6) showed that the charge transfer resistance $\left(R_{\mathrm{ct}}\right)$ of Ni-LVO $(62 \Omega)$ was smaller than that of the pristine LVO $(95 \Omega)$. The improved conductivity of $\mathrm{Ni}-\mathrm{LVO}$ is probably the result of the presence of lower-valence vanadium ions $\left(\mathrm{V}^{4+}\right)$ within Ni-LVO. ${ }^{28-30}$ As shown in Table 1, the lithium diffusion coefficients $(D)$ calculated by the Nyquist data below $1.0 \mathrm{~Hz}$ were $1.49 \times 10^{-15}$ and $2.02 \times 10^{-15} \mathrm{~cm}^{2} \mathrm{~s}^{-1}$ for the LVO and Ni-LVO electrodes, respectively, thus suggesting that the Ni-LVO electrode has faster kinetics for lithium ion insertion/extraction. These results indicate that the Ni-LVO presents smaller charge transfer resistance and a higher lithium diffusion coefficient than LVO, which are favorable for improving the lithium ion storage and are consistent with the electrochemical results discussed previously.

The electrochemical performance of both $\mathrm{LVO}$ and $\mathrm{Ni}-\mathrm{LVO}$ samples were measured between 0.01 and $3.0 \mathrm{~V}$ vs $\mathrm{Li}^{\prime} / \mathrm{Li}^{+}$at different current densities, ranging from 50 to $4000 \mathrm{~mA} \mathrm{~g}^{-1}$. In Figure $7 \mathrm{a}$, both LVO and Ni-LVO displayed much larger discharge capacity during the first cycle at the current density of $50 \mathrm{~mA} \mathrm{~g}^{-1}$; the second discharge capacity of the electrode was lower than the initial discharge, and the large, irreversible capacity was attributed to the formation of the solid electrolyte interface film. At $50 \mathrm{~mA} \mathrm{~g}^{-1}$, the discharge capacities for LVO and Ni-LVO electrodes were higher than the theoretical value $\left(591 \mathrm{mAh} \mathrm{g}^{-1}\right)$. The extra capacity at low potential may be related to the decomposition of the electrolyte upon reduction with the formation of a gel-like polymeric film ${ }^{31}$ and interfacial storage, ${ }^{32,33}$ which has also been observed in other anode materials such as $\mathrm{SnO}_{2},{ }^{34}$ $\mathrm{CoO}^{35}$ and $\mathrm{CoS}_{x}{ }^{36}$

The capacity of the LVO electrode decreased rapidly at $50 \mathrm{~mA} \mathrm{~g}^{-1}$. The Ni-LVO electrode exhibited higher capacity than the bare LVO electrode. The discharge capacities of the Ni-LVO electrode were $\sim 595,535,441,338,267$ and $191 \mathrm{mAh} \mathrm{g}^{-1}$ at current densities of 100, 200, 500, 1000, 2000 and $4000 \mathrm{~mA} \mathrm{~g}^{-1}$, respectively. For the LVO electrode, the capacities were found to be only 447, 372, 286, 208, 132 and $79 \mathrm{mAh} \mathrm{g}^{-1}$ at the corresponding current densities. When the current density returned to $50 \mathrm{mAg} \mathrm{g}^{-1}$, the capacity of the Ni-LVO was still $576 \mathrm{mAh} \mathrm{g}^{-1}$, but it decreased to $342 \mathrm{mAh} \mathrm{g}^{-1}$ for the LVO. The second discharge capacity of the electrode was lower than the initial discharge, resulting from the formation of the solid electrolyte interface film.

Figure $7 \mathrm{~b}$ shows the cycling stability of LVO and Ni-LVO electrodes at $1 \mathrm{Ag}^{-1}$. From the 10th cycle onward, the Ni-LVO exhibited very stable performance; nearly $100 \%$ capacity retention was obtained after 800 cycles. For Ni-LVO, the increase in capacity during cycling was also commonly observed for metal oxides and may be attributed to the improved lithium diffusion kinetics by the gradual activation process and reversible reaction between materials and electrolytes. ${ }^{36-38}$ For the LVO electrode, the discharge capacity decreased to $47 \%$ compared with the initial value. The coulombic efficiency of both LVO and
Ni-LVO electrodes remained constant close to $100 \%$. Thus, nickel doping not only facilitates the lithium ion transport on the Ni-LVO sample but also has a positive effect on the structural stability during cycling at high current density.

Superior lithium ion storage and long-term durability of the $\mathrm{Ni}-\mathrm{LVO}$ as an anode in lithium-ion batteries can be derived from nickel doping. First, nickel doping increases the surface energy of $\mathrm{Ni}-\mathrm{LVO}$, which facilitates electrolyte transport at the intercalation/ extraction on the surface. Second, the greater amorphousness, defect-like oxygen vacancies and local lattice distortion induced by low-valence nickel doping result in the formation of nucleation centers for phase transformation and reduce the interaction between cations and anions during the lithium intercalation/extraction processes. ${ }^{12}$

\section{CONCLUSIONS}

Nickel-doped LVO nanocrystallites synthesized at room temperature were demonstrated to possess more amorphousness, $\mathrm{V}^{4+}$ and oxygen vacancies, which in turn led to a small overpotential and fast reaction kinetics. Surface energy determined by inverse gas chromatography revealed that Ni-LVO possesses high surface energy that facilitates the intercalation reaction at the interface with the electrolyte. As an anode material, Ni-LVO exhibits excellent lithium-ion storage properties with capacities of $650 \mathrm{mAh} \mathrm{g}^{-1}$ at $50 \mathrm{mAh} \mathrm{g}^{1}, 338 \mathrm{mAh} \mathrm{g}^{-1}$ at $1 \mathrm{Ag}^{-1}$ and $191 \mathrm{mAh} \mathrm{g}^{-1}$ even at $4 \mathrm{Ag}^{-1}$. After 800 cycles at $1 \mathrm{Ag}^{-1}$, the Ni-LVO maintains nearly $100 \%$ of the initial reversible capacity.

\section{CONFLICT OF INTEREST}

The authors declare no conflict of interest.

\section{ACKNOWLEDGEMENTS}

This work was supported by China's Thousand Talents program for pioneering research, the Postdoctoral Science Foundation of China (2015M570987), the National Science Foundation of China (51374029), the Program for New Century Excellent Talents in University (NCET-13-0668) and Fundamental Research Funds for the Central Universities (FRF-TP-14-008C1).

1 Zhang, C., Song, H., Liu, C., Liu, Y., Zhang, C., Nan, X. \& Cao, G. Fast and Reversible Li Ion Insertion in Carbon-Encapsulated $\mathrm{Li}_{3} \mathrm{VO}_{4}$ as Anode for Lithium-Ion Battery. Adv. Funct. Mater. 25, 3497-3504 (2015).

2 Rodger, A. R., Kuwano, J. \& West, A. R. Li+ ion conducting $\gamma$ solid solutions in the systems $\mathrm{Li}_{4} \mathrm{XO}_{4}-\mathrm{Li}_{3} \mathrm{YO}_{4}: \mathrm{X}=\mathrm{Si}, \mathrm{Ge}, \mathrm{Ti} ; \mathrm{Y}=\mathrm{P}, \mathrm{As}, \mathrm{V} ; \mathrm{Li}_{4} \mathrm{XO}_{4}-\mathrm{LiZO}_{2}: \mathrm{Z}=\mathrm{Al}, \mathrm{Ga}, \mathrm{Cr}$ and $\mathrm{Li}_{4} \mathrm{GeO}_{4}-\mathrm{Li}_{2} \mathrm{CaGeO}_{4}$. Solid State lonics 15, 185-198 (1985).

$3 \mathrm{Li}, \mathrm{H}$., Liu, X., Zhai, T., Li, D. \& Zhou, H. $\mathrm{Li}_{3} \mathrm{VO}_{4}$ : a promising insertion anode material for lithium-ion batteries. Adv. Energy Mater. 3, 428-432 (2013).

4 Song, X. Q., Jia, M. Y. \& Chen, R. F. Synthesis of $\mathrm{Li}_{3} \mathrm{VO}_{4}$ by the citrate sol-gel method and its ionic conductivity. J. Mater. Process. Technol. 120, 21-25 (2002)

5 Zhang, P., Zhao, L., An, Q., Wei, Q., Zhou, L., Wei, X., Sheng, J. \& Mai, L. A high-rate $\mathrm{V}_{2} \mathrm{O}_{5}$ hollow microclew cathode for an all-vanadium-based lithium-ion full cell. Small 12, 1082-1090 (2016)

6 Liang, Z., Lin, Z., Zhao, Y., Dong, Y., Kuang, Q., Lin, X., Liu, X. \& Yan, D. New understanding of $\mathrm{Li}_{3} \mathrm{VO}_{4} / \mathrm{C}$ as potential anode for Li-ion batteries: Preparation, structure characterization and lithium insertion mechanism. J. Power Sources 274, 345-354 (2015)

7 Ni, S., Lv, X., Zhang, J., Ma, J., Yang, X. \& Zhang, L. The electrochemical performance of lithium vanadate/natural graphite composite material as anode for lithium ion batteries. Electrochim. Acta 145, 327-334 (2014).

8 Zhang, C., Liu, C., Nan, X., Song, H., Liu, Y., Zhang, C. \& Cao, G. Hollow-cuboid $\mathrm{Li}_{3} \mathrm{VO}_{4} / \mathrm{C}$ as high-performance anodes for lithium-ion batteries. ACS Appl. Mater. Interfaces 8, 680-688 (2016).

9 Li, Q., Sheng, J., Wei, Q., An, Q., Wei, X., Zhang, P. \& Mai, L. A unique hollow $\mathrm{Li}_{3} \mathrm{VO}_{4} /$ carbon nanotube composite anode for high rate long-life lithium-ion batteries. Nanoscale 6, 11072-11077 (2014).

10 Liu, J., Lu, P.-J., Liang, S., Liu, J., Wang, W., Lei, M., Tang, S. \& Yang, Q. Ultrathin $\mathrm{Li}_{3} \mathrm{VO}_{4}$ nanoribbon/graphene sandwich-like nanostructures with ultrahigh lithium ion storage properties. Nano Energy 12, 709-724 (2015). 
11 Shi, Y., Wang, J.-Z., Chou, S.-L., Wexler, D., Li, H.-J., Ozawa, K., Liu, H.K. \& Wu, Y. P. Hollow structured $\mathrm{Li}_{3} \mathrm{VO}_{4}$ wrapped with graphene nanosheets in situ prepared by a one-pot template-free method as an anode for lithium-ion batteries. Nano Lett. 13, 4715-4720 (2013).

12 Liu, C., Neale, Z. G. \& Cao, G. Understanding electrochemical potentials of cathode materials in rechargeable batteries. Mater. Today 19, 109-123 (2016).

13 Chen, L., Jiang, X., Wang, N., Yue, J., Qian, Y. \& Yang, J. Surface-amorphous and oxygen-deficient $\mathrm{Li}_{3} \mathrm{VO}_{4-\delta}$ as a promising anode material for lithium-ion batteries. Adv. Sci. 2, 1500090 (2016).

14 Zheng, Y.-Z., Ding, H., Uchaker, E., Tao, X., Chen, J.-F., Zhang, Q. \& Cao, G. Nickelmediated polyol synthesis of hierarchical $\mathrm{V}_{2} \mathrm{O}_{5}$ hollow microspheres with enhanced lithium storage properties. J. Mater. Chem. A 3, 1979-1985 (2015).

15 Milczewska, K. \& Voelkel, A. in Characterization of Polymer Blends (ed.Thomas S., Grohens Y. \& Jyotishkumar P.) Ch. 10, 327-346 (Wiley-VCH Verlag GmbH \& Co. KgaA, Weinheim, Germany, 2014).

16 Mukhopadhyay, P. \& Schreiber, H. P. Aspects of acid-base interactions and use of inverse gas chromatography. Colloids Surf. A Physicochem. Eng. Asp. 100, 47-71 (1995).

17 Chae, O. B., Kim, J., Park, I., Jeong, H., Ku, J. H., Ryu, J. H., Kang, K. \& Oh, S. M. Reversible Lithium Storage at Highly Populated Vacant Sites in an Amorphous Vanadium Pentoxide Electrode. Chem. Mater. 26, 5874-5881 (2014).

18 Uchaker, E., Zheng, Y. Z., Li, S., Candelaria, S. L., Hu, S. \& Cao, G. Z. Better than crystalline: amorphous vanadium oxide for sodium-ion batteries. J. Mater. Chem. A 2, 18208-18214 (2014).

19 Radich, J. G., Chen, Y.-S. \& Kamat, P. V. Nickel-doped $\mathrm{MnO}_{2}$ nanowires anchored onto reduced graphene oxide for rapid cycling cathode in lithium ion batteries. ECS J. Solid State Sci. Technol. 2, M3178-M3181 (2013).

20 Biesinger, M. C., Payne, B. P., Grosvenor, A. P., Lau, L. W. M., Gerson, A. R. \& Smart, R. S. C. Resolving surface chemical states in XPS analysis of first row transition metals, oxides and hydroxides: $\mathrm{Cr}, \mathrm{Mn}, \mathrm{Fe}, \mathrm{Co}$ and Ni. Appl. Surf. Sci. 257 2717-2730 (2011).

21 Gamelas, J. A. F., Ferraz, E. \& Rocha, F. An insight into the surface properties of calcined kaolinitic clays: the grinding effect. Colloids Surf. A Physicochem. Eng. Asp. 455, 49-57 (2014).

22 Shah, U. V., Wang, Z., Olusanmi, D., Narang, A. S., Hussain, M. A., Tobyn, M. J. \& Heng, J. Y. Effect of milling temperatures on surface area, surface energy and cohesion of pharmaceutical powders. Int. J. Pharm. 495, 234-240 (2015).

23 Dorris, G. M. \& Gray, D. G. Adsorption of n-alkanes at zero surface coverage on cellulose paper and wood fibers. J. Colloid Interface Sci. 77, 353-362 (1980).

24 Schultz, J., Lavielle, L. \& Martin, C. The role of the interface in carbon fibre-epoxy composites. J. Adhesion 23, 45-60 (1987).

25 Fowkes, F. M. Attractive forces at interfaces. Ind. Eng. Chem. 56, 40-52 (1964).

26 Maciejewska, M., Krzywania-Kaliszewska, A. \& Zaborski, M. Surface properties of calcium and magnesium oxide nanopowders grafted with unsaturated carboxylic acids studied with inverse gas chromatography. J. Chromatogr. A 1257, 141-148 (2012).

27 Przybyszewska, M., Krzywania, A., Zaborski, M. \& Szynkowska, M. I. Surface properties of zinc oxide nanoparticles studied by inverse gas chromatography. J. Chromatogr. A 1216, 5284-5291 (2009).
28 Li, Y., Yao, J., Uchaker, E., Zhang, M., Tian, J., Liu, X. \& Cao, G. Sn-Doped $V_{2} \mathrm{O}_{5}$ Film with Enhanced Lithium-Ion Storage Performance. J. Phys. Chem. C 117 23507-23514 (2013)

29 Yu, H., Rui, X., Tan, H., Chen, J., Huang, X., Xu, C., Liu, W., Yu, D. Y., Hng, H. H., Hoster, H. E. \& Yan, Q. Cu doped $\mathrm{V}_{2} \mathrm{O}_{5}$ flowers as cathode material for high-performance lithium ion batteries. Nanoscale 5, 4937-4943 (2013).

30 Zhang, C., Yu, H., Li, Y., Gao, Y., Zhao, Y., Song, W. \& Yi, B. Supported noble metals on hydrogen-treated $\mathrm{TiO}_{2}$ nanotube arrays as highly ordered electrodes for fuel cells. ChemSusChem. 6, 659-666 (2013).

31 Ponrouch, A., Taberna, P.-L., Simon, P. \& Palacín, M. R. On the origin of the extra capacity at low potential in materials for $\mathrm{Li}$ batteries reacting through conversion reaction. Electrochim. Acta 61, 13-18 (2012).

32 Zhukovskii, Y. F., Balaya, P., Kotomin, E. A. \& Maier, J. Evidence for interfacial-storage anomaly in nanocomposites for lithium batteries from first-principles simulations. Phys. Rev. Lett. 96, 058302 (2006).

33 Jamnik, J. \& Maier, J. Nanocrystallinity effects in lithium battery materials aspects of nano-ionics. Part IV. Phys. Chem. Chem. Phys. 5, 5215-5220 (2003).

34 Wang, X., Li, Z., Zhang, Z., Li, Q., Guo, E., Wang, C. \& Yin, L. Mo-doped $\mathrm{SnO}_{2}$ mesoporous hollow structured spheres as anode materials for high-performance lithium ion batteries. Nanoscale 7, 3604-3613 (2015).

35 Guan, H., Wang, X., Li, H., Zhi, C., Zhai, T., Bando, Y. \& Golberg, D. CoO octahedral nanocages for high-performance lithium ion batteries. Chem. Commun. 48, 4878-4880 (2012)

36 Wu, R., Wang, D. P., Rui, X., Liu, B., Zhou, K., Law, A. W. K., Yan, Q., Wei, J. \& Chen, Z. In-situ formation of hollow hybrids composed of cobalt sulfides embedded within porous carbon polyhedra/carbon nanotubes for high-performance lithium-ion batteries. Adv. Mater. 27, 3038-3044 (2015).

37 Wang, D., Yang, J., Li, X., Geng, D., Li, R., Cai, M., Sham, T.-K. \& Sun, X. Layer by layer assembly of sandwiched graphene/SnO2 nanorod/carbon nanostructures with ultrahigh lithium ion storage properties. Energy Environ. Sci 6, 2900-2906 (2013).

38 Zou, F., Hu, X., Li, Z., Qie, L., Hu, C., Zeng, R., Jiang, Y. \& Huang, Y. MOF-derived porous $\mathrm{ZnO} / \mathrm{ZnFe}_{2} \mathrm{O}_{4} / \mathrm{C}$ octahedra with hollow interiors for high-rate lithium-ion batteries. Adv. Mater. 26, 6622-6628 (2014).

This work is licensed under a Creative Commons

Attribution 4.0 International License. The images or other third party material in this article are included in the article's Creative Commons license, unless indicated otherwise in the credit line; if the material is not included under the Creative Commons license, users will need to obtain permission from the license holder to reproduce the material. To view a copy of this license, visit http:// creativecommons.org/licenses/by/4.0/

(C) The Author(s) 2016

Supplementary Information accompanies the paper on the NPG Asia Materials website (http://www.nature.com/am) 